\title{
Digital exclusion in later life: A Maltese case study
}

\author{
Marvin Formosa \\ European Centre for Gerontology, University of Malta, Msida MSD 2080, Malta
}

Email address:

marvin.formosa@um.edu.mt

\section{To cite this article:}

Marvin Formosa. Digital Exclusion in Later Life: A Maltese Case Study. Humanities and Social Science.

Vol. 1, No. 1, 2013, pp. 21-27. doi: 10.11648/j.hss.20130101.14

\begin{abstract}
Information and communication technologies (ICTs) are driving profound changes in the way in which individuals, organizations and governments interact. In particular, the internet has been a major force behind the development towards a more globalized, knowledge-based economy. However, in terms of access to computer access and internet usage, a digital divide between the 'haves' and the 'have nots' has long been recognized. One key sector of non-users consists of older persons. For various reasons, including no exposure to computers over their lifetime and in their occupations, income levels, physical disability and access to affordable ICT training, only limited percentages of older people have adequate ICT skills. A growing concern has been that older adults who do not engage with ICTs face social disadvantages and exclusion. This article reports upon a qualitative study with older non-users of ICTs, with its key goal being to understand what leads to, and the effects of, digital exclusion in later life. Results found that older persons who never made use of ICTs were significantly delineated by gender and socio-economic status patterns - namely, women (especially housewives, who had never been in paid employment), individuals who worked in blue-collar and working-class occupations, and the long-term unemployed. Data also demonstrated that access was not the main issue at hand, and that the failure of older adults to become digital citizens was the result of a continuum of overlapping barriers. This study provided information highlighting the rationales and motivations underlying individuals' non-use of computers - namely, believing that they were now 'too old' to use new technologies, a lack of relevance or 'life-fit' of computers, perceived non-usefulness and difficulty to use, anxiety about computer usage, concern about security and privacy issues, and the facing of disability issues.
\end{abstract}

Keywords: Digital Exclusion, Information and Communication Technologies, Older Adults, Later Life, Malta

\section{Introduction}

These are exciting times for both gerontologists and e-specialists. On one hand, as a result of declining fertility and mortality levels, many countries throughout the world registered major improvements of life expectancy at birth. Among the nations, Japan, Monaco, and most European countries are considered the oldest nations, with between 17 and 23 per cent of persons being aged 65 and over [1]. On the other hand, information and communication technology (ICT) continues to be a major driver of economic and social modernization. In 2008, European companies have devoted 20 per cent of their investment to ICTs and the sector accounts for 26 per cent of overall research expenditure [2].

Yet, all that glitters is not gold, as one also witnesses that the level of computer access and Internet use remains unbalanced across all the European Union (EU) Member States. This article reports upon a case study on digital exclusion in later life in Malta. The Maltese archipelago is an EU
Member State, lying at the heart of the Mediterranean Sea, and consisting of three islands: Comino, Gozo and Malta. Comino is uninhabited, and with Gozo having just a population of 31,143 persons, leaves Malta as the major island of this archipelago state, with as much as 384,912 residents [3]. In Malta, older adults present a lower use of computers and Internet compared with younger segments of the population. Specifically, in 2010 only 47.8 and 44.3 per cent of adults aged in the 55-74 age bracket used computers and the Internet respectively. Whilst the "digital natives get a headstart as they grow up exposed and familiar with ICT...older generations fall into a vicious circle of non-adoption as they find themselves alien to the cues and metaphors of this new environment" [4]. This is problematic since older persons' exclusion from the digital era could impact negatively upon their social and economic welfare, and on their quality of life. The Internet can surely contribute to the creation of an active senior population, decreasing the rate of marginalization and social isolation. Indeed, e-competence has a potentially positive effect on older persons' autonomy and cogni- 
tion-related issues, whilst improving daily functioning.

This article puts the spotlight on older persons who are non-users of ICTs, highlighting the barriers they face in becoming e-literate and e-competent. Whilst the first section introduces the concept of digital citizenship, the next section embeds this notion in a gerontological perspective. The third section discusses the concept of the 'digital age divide'. Whilst the fourth section describes the research design underlying the case-study, the sixth part presents the results and discussion of the elicited data. The final part brings the article to a close by documenting the most significant inferences emerging from the study.

\section{Digital Citizenship}

Information and communication technologies have been driving profound changes in the ways in which groups and individuals experience citizenship. Information technology, without doubt, has assumed a secure place in contemporary societies and the prevailing standards of global society. In particular, the emergence of a pervasive online community has been a major force behind the push towards a more globalized, knowledge-based economy. A strong implication of this argument is that, in contemporary times, digital competence is a necessary element for full citizenship. Due to the explosion of political information on the web, digital citizenship is an enabling factor for the civil, political and rights of membership. As Mossberger and colleagues highlighted, "in much the same way as education has promoted democracy and educational growth, the Internet has the potential to benefit society as a whole, and facilitate the membership and participation of individuals as a society" [5]. A digital citizen refers to a person utilizing information technology in order to engage in society, politics, and government participation. Hence, digital citizens are those who use the Internet every day, and because frequent use requires some regular means of access (usually at home), some technical skill, and the educational competencies to perform tasks such as finding and using information on the web, are all key characteristics of digital citizenship [6].

Policy literature highlights that, to qualify as a digital citizen, a person generally must have extensive skills, knowledge, and access of using the Internet through computers, mobile phones, and web-ready devices to interact with private and public organizations [6]. However, digital citizenship is not solely about leisureliness and relaxation. Embedding the concept in the framework of Marshall's outlook on citizenship's three traditions - liberalism, republicanism, and ascriptive hierarchy - digital citizenry can occur alongside the promotion of equal economic opportunity, as well as increased political participation and civic duty [6]. This is because digital citizenship eliminates various exclusionary elements of ascriptive hierarchy. Indeed, the Internet does not exclude those who wish to participate in its realm on the basis of race, religion, or class statuses elements which previously had the potential to exclude people from engaging in active citizenship.
One locates four key benefits of digital citizenship for society in general and older persons in particular [5]. First, digital citizenship has the potential to bring about higher levels of productive ageing as it equips older persons with those skills that are necessary for gaining and holding on to jobs. ICT can assist and compensate for functional restrictions, and therefore improve the employability of people who are at risk of being excluded from the labor market. The introduction of ICT can change the structural organization of work, making it more flexible and offering opportunities for innovative working environments that better fit with individual responsibilities and restrictions that tend to increase with age. Second, digital citizenship enables older people to connect with others in their communities. Nowadays, not only is internet use more widespread, but is also creating novel models of online organization that emphasize political and social community rather than isolation. Community is becoming embedded in personal social networks rather than in communal organizational structures. The Internet may help people to connect in the virtual world, and facilitate social interaction by providing easy access to relevant information, and reducing transaction costs to meet other people in such places as theatres, concerts, and bars. Third, the Internet has become an integral route towards higher levels of civic and political engagement. Existing research has established a positive link between Internet use and political participation, ranging from voter turnout to campaign contributions to citizen-initiated contact with government. For example, during the 2006 United States mid-election, 31 per cent of all internet users engaged in some campaign-related activity online and 15 per cent of internet users relied on the internet as their most important source of news [7]. And finally, ICT can play a key role in engaging older adults in lifelong learning. Digital competency serves as a catalyst for improved levels of lifelong learning in later life as it supports formal, non-formal and informal learning opportunities. ICT holds a central role in a knowledge society in order to reap the full benefit from the learning resources and services available. As emphasized by Ala-Mutka, "ICT in its different forms (computers, internet, mobile phones, CDs) enable new ways of accessing learning resources, both for organized courses and informal learning" [8]. At the same time, "ICT can compensate disabilities and also provide more flexible learning models by combining self-managed and organized education" [8].

\section{Digital Citizenship in Later Life}

International and national policies focusing on the interface between ageing and digital citizenship abound in present times. The EU is surely no exception as it strives to transform Europe into "the most competitive and dynamic knowledge-based economy in the world" [9]. Indeed, recent years witnessed an increasing emphasis on behalf of policy makers on the potential of ICTs to improve the quality of life of older persons. The EU initiative i2010 - A European in- 
formation society for growth and employment aims to promote [10] an inclusive European information society and to make Europe more attractive to investment and innovation in knowledge-based goods and services. On similar lines, the Declaration resulting from the Ministerial Conference ICT for an inclusive society [11] held in Riga in June 2006 underlines the need to address ICT solutions for active ageing. Stressing that the contribution of civil society, industry and all other stakeholders is essential, the declaration suggests that special attention should be given to addressing the needs of older people by exploiting the full potential of the internal market of ICT services and products for the older people, improving the employability, working conditions and work-life balance of older workers, enhancing active participation in the society and economy and self-expression, and realizing increased quality of life, autonomy and safety. One flagship initiative linked with the i2010 that illustrates the potential of ICT to improve quality of life is Ageing well in the information society [12] which addresses the potential of ICT for well-being, independent living, health ageing, and work-life balance in later life. Ageing well in the information society supports EU policy in meeting the goals of the revised Lisbon agenda: "the information society can enable older people - when and where they wish to do so - to participate fully in society and the economy, and to be active as empowered citizens; and at the same time generate benefits for businesses and for economy and society at large" [12].

There is no doubt that setting up of policies advocating improved levels of digital citizenship in later life is especially opportune when one considers that e-competence improves the physical, psychological and social well-being of older adults $[13,14]$. The stereotypical assumptions that computers are only for younger persons, the virtual world is too complicated for seniors, the digital revolutions has no impact on successful ageing, and that older persons have no place in online social networking, have long been dropped. In their stead, one finds that a rigorous exploration of the interface between e-competence and later life has emerged as a vital element of the inclusion policies of both national governments and the EU. Nowadays, there is a growing awareness that ICT can be of great significance leading older citizens towards higher degrees of active, successful and productive ageing. This is because novel technologies help older adults to work longer, stay active and live independently - all of which are crucial if older generations are viewed as a resource rather than a burden. Without a higher level of participation of the elder population in employment, and without better tailored and more effective health- and social care services, these trends will put serious pressure on Europe's social models and public finances.

ICTs have a key role to play to overcome these challenges, having a strong potential to address the daily difficulties that older people face - whether medical, physical or social - and keeping them active at work and community. Indeed, research found computer access and Internet use to have a positive effect on older adult's autonomy and cogni- tion-related issues, preventing people from cognitive decline and improving autonomy and everyday functioning [15]. It is particularly valuable to elders living alone, widowed, living in rural environments, or who have mobility restrictions. Programs offering older adults an opportunity to acquire and sharpen computer-related skills reported increased feelings of social support and connectivity, whilst reducing technology-related anxiety [16]. Older adults who use computers have also been found to experience positive outcomes that include improvement in their overall productivity and in the activities of their daily living, whilst also increasing self-esteem and feelings of self-control. Many studies have, in fact, located positive influences of maintaining cyberspace communication on older adults' mental well-being, with results locating a negative relationship between support network participation and perceived life stress [17]. Other beneficial outcomes of using a home computer are especially true for people who are likely to experience increased vulnerability as they age. For example, technology use could potentially support the functional independence of older people and, thus, enable them to continue living independently in their own homes [18]. In fact, one finds various online communities that provide older learners the opportunity to address issues such as financial decisions, healthy lifestyle, management of disabilities and illness, friendships, relationships, passions, hobbies, work, and connection with family and friends. Wright's study also uncovered a negative linear relationship between online participation and perceived life stress with older adults who spent more time on-line were more satisfied with their Internet support network and felt less stress than those who spent less time [19]. Ng's exploration of how and why a selected group of older learners enrolled in a computing literacy program is a case in point as it presented valid data on the perceived personal benefits of digital citizenship in later life [20].

\section{The Digital Age Divide}

One central concern in present times concerns the uneven and unequal take up of digital citizenship as social analysts document a persistent 'digital' divide that was seen as exacerbating many of the existing inequalities within national and global society. The digital divide commonly refers to the gap between those who do and those who do not have access to new forms of information technology. Most often these forms are computers and their networks, but other digital equipment such as mobile telephony and digital television are sometimes also included. Of course, the interpretive framework for this divide is still being debated. Whilst some stressed the uneven development of most technologies, where uptake is fastest amongst the more affluent but which diffuse over time across social and national barriers, others emphasized the persisting social inequalities upon which the digital divide is superimposed. It is the latter issue that concerns this research project, a concern that revolved around both vertical and horizontal dimensions of the digital 
divide. In addition to gender, socio-economic background, and geographical space, 'age' is a crucial variable in research on the digital divide. As Abbey and Hyde [21] documented, across all industrial countries, and indeed the world, the older you are the less likely are you to use ICTs. For instance, in the United Kingdom 90 per cent of those in the 16-24 age group had accessed the internet in the three months prior to one particular survey, only 24 per cent of those aged 65-plus had in the same period [22]. In addition, a Eurostat survey of individuals' use of computers and internet in 2004 found the lowest use to be among those aged 65 and over, with around 10 per cent using the Internet [21]. In America, as of April 2012, 53 per cent of American adults ages 65-plus the internet or email. Though older adults are still less likely than all other age groups to use the internet, it is nevertheless positive to note that the latest data found that for the first time that half of seniors are going online. After several years of very little growth among this group, these gains are significant [21].

Turning our attention to Malta, local statistics also reveal that older cohorts are personified by lower levels of digital citizenship when compared to younger peers. The Culture Participation Survey 2011 [23] includes information on patterns of ICT amongst older Maltese. Of the surveyed population aged 65-plus, 28.8 per cent reported that they had access to the internet only at home during the 12 months preceding the survey. On the other hand, 68.6 per cent reported that they had no access to the internet. The percentage of respondents who responded positively to internet access both at home and elsewhere was 0.8 , while 1.7 per cent could access the internet in places other than home. Respondents were asked the reasons why they used the internet. Forty per cent of older respondents used the internet for private purposes, whilst the remaining users made use of the internet for leisure activities such as downloading/uploading, watching movies, listening to music, games, peer-to-peer and podcast (39.9 per cent), and the purchase of cultural goods and services such as films, music, books, magazines, e-learning material, computer software and tickets for events (19.2 per cent). Another survey which forwarded further data on ICT patterns in later life Malta reported that, in 2010, individuals in the 65-74 age bracket are the least likely to own a computer, with computer availability estimated at 38 per cent [24]. Percentage figures for computer users aged in the '55-64' and '65-74' age brackets were 33.7 and 14.1 respectively. Results also showed that internet users aged between 65 and 74 were the least likely to make use of e-Government services (49 per cent), and that only 25.6 and 11.9 per cent of persons aged in the ' $55-64$ ' and ' $65-74$ ' age brackets received some form of computer training in the three years preceding the date when the survey was administered. The gap between older Maltese and international needs to be addressed urgently since an inability to make use of ICT exposes individuals to unemployment risks, and limits the capacity and flexibility of the Maltese workforce.

Research documenting the digital age divide has also strived to understand the reasons leading older people to being interested in or not interested in computers and the Internet. One detailed study reports on the results of two connected surveys of computer and Internet use among the older population in the United Kingdom [25]. Many older adults interviewed in this study reported that their lack of interest in using a computer was due to 'age, as they felt too old', whilst others simply replied that they 'are not interested', 'don't want to', 'can't be bothered', or that they perceive computer usage to 'require too much effort as such machines are too complicated'. Some even believed that computers are not really useful, whilst others blamed their physical discomfort and/or accessibility issues. A significant number of older persons prefer to take advantage of other people's skills, especially their offspring, rather than figuring out how to use a computer themselves. As regards the lack of interest in using the internet, older non-users signaled 'lack of interest', 'lack of access to computers', 'lack of access to the internet', and again, 'feeling too old'. Others commented that the internet is 'not a technology for our age group, but something for younger people' or that there is 'no need for internet access, since family and friends live close by. Another study reported that older adults who report experiencing anxiety were less likely to report using the internet, while of those people who said they did not experience anxiety, the majority were more likely to use the internet than not [26]. The same study also found that older adults who reported not using the internet were more likely to say that they 'often' felt lonely. Conversely, people who do not use the internet were more likely to respond that they 'hardly ever or never' felt lonely. Moreover, older persons who reported using the internet were more likely to report having higher-than-average qualifications, as was the case with peers having relatively affluent household income.

\section{Research Design}

The study aimed to explain the relative lack of digital competence and internet use amongst older persons in the Maltese Islands, capturing the reasons as why many older adults remain outside the digital revolution, as well as the effects that this state of affairs has on their quality of life. The goals of the study included understanding as why many older adults remain outside the digital revolution, having neither access to computers nor internet, as well as to research the effect of digital exclusion on their quality of lives. The research objectives sought the identification of (if any) the psychological, social, material, health-related, and institutional barriers to reaching satisfactory levels of digital competence in later life. The research process occurred through five key stages, commencing in September 2012 until June 2013 when the final report was finalized. Following an initial determination of the research agenda, the second stage consisted in developing and collating the literature review. The third stage consisted of deliberation upon the most suitable research design and tool of data collection, whereby it was concluded that the research's aims/objectives necessitated a qualitative design that utilized 
semi-structured interviews. In semi-structured interviews, the interviewer is normally required to ask specific openended questions but is free to probe beyond them if necessary, with the interview developing as a joint product of what the interviewees and interviewers talk with each other. The fourth stage consisted in piloting work and data collection. The interview questions are presented below:

\section{Ice-breaker and exploratory queries}

Do you own a mobile phone? How old were you when you started using one? What do you use it for? Is it a smartphone? How do you feel about computers and the internet, and their role in Maltese society? Do you think that, nowadays, it is necessary to know how to use computers and surf the internet?

\section{Research questions}

Do you have access to a computer? Is the cost of purchasing a computer and/or internet service an issue in gaining access to a computer and internet services? What's your opinion on the potential of computers and internet surfing in today's society? Are there are benefits of knowing and actually using computers and internet surfing? Do you think that one is disadvantaged if he/she does not use computers/internet? Do you feel that computers and internet services are best suited to younger persons? Do you harbor any concern or anxiety to using computers? Do you feel that computer-training sessions are available in your community? Are you interested/motivated to use the computer/internet in your life? Do you feel that physical problems hinder you from using the computer? Do you feel that mental problems hinder you from using the computer? What other obstacles do you are hindering you from using computers and the internet?

Closure questions

Do you see yourself making an effort to learn to use the computer in the coming future? Do you feel that the world is better or worse with the dominance of computers and internet? Do you have anything you want to add to what you have said during the interview?

Interviews were conducted with 66 older adults, all aged 55 years and above, by a research assistant (51) and the author (15). Both interviewers ensured unfailing adherence to ethical principles (autonomy, beneficence, non- maleficence, justice) and rules (veracity, privacy, confidentiality, fidelity) of ethical conduct. The final stage consisted in the rigorous analysis of data which resulted in the major themes presented in subsequent section of this report. Data was analyzed through 'logical analysis' which first located premises within data that symbolize one group, and then exploring connections between groups, and 'qualitative factoring' which transforms data in 'qualitative' hypothetical opposites [27].

\section{Results and Discussion}

Data showed that the patterns of older persons who never made use of ICTs was significantly delineated by gender and socio-economic status - namely, women (especially housewives, who had never been in paid employment), individuals who worked in blue-collar and working-class occupations, and the long-term unemployed. Marital status, educational background, and health status were also noticeable predictors of digital exclusion as widows and older persons reporting to experience some form of disability were numerous amongst the selected interviewees. Moreover, those who leave full-time education early, and have no educational qualifications, were less likely to have made use of a computer during their lifetime, especially as many work in occupations in which skills in ICT are not required or essential. With respect to geographical space, living in a rural locality and deprived neighborhood were other strong predictors of digital exclusion.

This study provided information as why digital exclusion is prevalent amongst older adults, highlighting the rationales and motivations underlying individuals' non-use of computers. It demonstrated that non-participants tended to look back and to dwell upon the past rather than what the future will bring, and were relatively estranged from contemporary society and reluctant to take a more active part in its social discourse. Indeed, many interviews professed introvert and fatalist attitudes towards their life and society in general.

Data demonstrated that access was not the main issue at hand, and that the failure of elders to become digital citizens was the result of a continuum of overlapping barriers. After all, the Government has set up computers and internet terminals in all Day Centres for the Elderly in its commitment to give everyone the opportunity to become digital citizens. Similarly, cost did not emerge a prohibitive factor in computer and online access. One prominent barrier to engaging with ICTs included the belief that the internet is the preserve of the young and how they were now 'too old' to use ICT: "Computers belong to the world of the younger generations. We are too old now. We missed the bus as far as computers are concerned. All these gadgets - computers, internet, and mobile phones - were never useful to me and they will never be. I am too old now. If I were younger, I would think otherwise, but I am not" (male, 72 years). Indeed, one key rationale that underlined interviewees' continued non-engagement with computers involved a lack of relevance or 'life-fit' of computers. Many claimed that they had no interest to use computers and/or surf the internet, and that for them, ICTs are irrelevant: "I have live my life without computers and I do not see why I should use them now. I am accustomed to waiting. If I need to phone my son, I can do that when I return home. If I want some information I can ask or look around in the village. I cannot imagine myself wasting my life looking inside a box" (female, 75 years).

Perceived usefulness and perceived ease of use were other key issues as many respondents claimed not to use the web because they saw no purpose for it in their lives. Most interviewees thought of the computer as an extremely complex tool, believing that navigation of the internet and especially smart phones, is extremely difficult and cumber- 
some: "My mind is too slow to learn how to fiddle with a computer. I do not think that it is easy to learn how to use a computer, and as they say 'go online'. Computers are really complex machines, and if you are not careful, they can take over your life. Even my some has problems, so you can imagine" (male, 69 years). It therefore results that anxiety about computer usage is highly related to digital exclusion, as it gives forth to negative emotional reactions - ranging from a desire to withdraw from the anxiety-provoking situation to the use or anticipated use of computers.

On parallel lines, a 'fear of new technology' was another common theme as many respondents worried they will break a computer by pressing the wrong key, a state of affairs that rendered them technophobic. Many expressed concern about security/privacy issues, usually fuelled by the media, believing that other people can easily access their data, spy on their activities, getting viruses on their computer, and being victims of fraud, especially when shopping online. In one respondent's words: "You cannot control computers. They are in control! I think that for a computer expert it is easy to see your mail and what you have on your computer. I think that its madness accessing your bank account from your computer" (female, 70 years).

Despite the fact that ICT provides many advantages for people with disabilities, data shows clearly that it also introduces new barriers of access. Older people experiencing physical and cognitive limitations - ranging from visual impairment to Parkinson's disease - found it hard to become digital citizens. Dexterity related problems, such as arthritis, were other common barriers since such disabilities hinder a person from using a keyboard or a mouse: "It is very difficult for me to use computers or mobile phones. My fingers are too large and my eyesight is not very good. When I look at a computer or phone I always realize how small they are. I also have arthritis and therefore find it very difficult, if not impossible, handle small things" (female 77 years).

Similar to global patterns [27], data demonstrated that older women's roles within the family - especially caring for frail relatives and young grandchildren - tend to limit their opportunities to use the Internet. Citing another respondent, "I have no time for computers. After I do what I have to do around the house, when my daughter does not bring her children on school holidays, I prefer to have a short lie-in. My husband is very god with computers but the he does not have to cook or hand up the clothes. I also prefer to go to church if I have time" (female, 70 years).

Older women, it results, have less time and fewer opportunities for leisurely web use, or to acquaint themselves with ICT, and a result, have lower confidence in, and a lower self-assessment of, their ICT skills. Lack of skill with computers was also raised by respondents, with many complaining about lack of support from family members and that their children lacked patience when assisting them with computer issues. Even when some plucked enough courage to enroll in computer courses, many felt lost and had encountered problems keeping space with the rest of the class to the extent that they dropped out: "At the training course, I always felt like a fish out of the water, I could not understand what the trainer is saying, and I did not even dream of asking any questions, as the other learners were doing well. There were only three of us out of 15 learners. We were considered as dead weight. We all dropped out eventually" (male 68 years). This shows that training programs that aim to increase an individual's knowledge about computer technology may not always be beneficial in reducing potential barriers and increasing the individual's perception of ease of use. As research has shown, training older adults may take distinct forms and in need to specific geragogical expertise and techniques, that provide reassurance and encouragement rather than simply technological objectives.

\section{Conclusion}

The engagement in digital citizenship in contemporary societies is an important factor in the full social inclusion of citizens, particularly as more public services go online. The age digital divide is a key stumbling block towards the achievement of a digital society where all citizens are not only fluent in digital competence but also use ICT so as to improve their quality of life. This study provided information as why digital exclusion is prevalent amongst older adults, highlighting the rationales and motivations underlying individuals' non-use of computers - namely, believing that they were now 'too old' to use new technologies, a lack of relevance or 'life-fit' of computers, perceived non- usefulness and difficulty to use, anxiety about computer usage, concern about security and privacy issues, disability issues, and being female. Undoubtedly, more research is needed to understand as why digital literacy declines with age and the extent that training and courses has a significant effect on the overcoming of those range of barriers that distance older adults from ICTs. It is also important that studies research what constitutes good practices in e-learning in later life, and the extent that older adults may become more attracted to the online world if web pages are more transparent, comprehensive, responsive, self-explanatory, adaptive, efficient, forgiving, flexible, informative and consistent with the user's other familiar designs. At the same time, it results from this study that mainstream computer training courses are not enough to coach and instruct older person in computer use and internet surfing, and that one needs learning initiatives developed and run by adult educators who are sensitive to the unique and situations circumstances facing persons in the latter phases of the life course.

\section{Acknowledgements}

I would like to acknowledge and thank the Malta Communications Authority for providing funds to carry out this study. Thanks also go to Dr. Andrea Rose Zammit who was employed as Research Support Officer on the project, and conducted the majority of interviews and first data analysis. 


\section{References}

[1] United Nations, World population prospects: The 2010 revision, Volume II: Demographic profiles. New York: United Nations, 2012.

[2] Commission for the European Communities, Innovation union competitiveness report 2011. Analysis part 1: Investment and performance in $R \& D$ - Investing in the future. Brussels: European Union.

[3] National Statistics Office, Census of population and housing 2011: Preliminary report. Malta: National Statistics Office, 2012.

[4] Malta Communications Authority, 2012, Networked Society: MCA's Digital Inclusion Strategy. Malta: Malta Communications Authority, 2012, pg. 12.

[5] Mossberger, K., Tolbert, C.J. and McNeal, R.S., Digital Citizenship: The internet, participation and society. Cambridge, MA: The MIT Press, 2009, pg. 1.

[6] Mossberger, K., Toward digital citizenship: Addressing inequality in the information age. In A. Chadwick \& P.N. Howard (eds.), The handbook of Internet politics. London: Routledge, 2009, pgs. 173-174.

[7] Rainie, L. and Horrigan, J., The number of Americans citing the internet as the source of most of their political news and information doubled since the last midterm election. Accessed 14/06/13, from http://www.pewinternet.org/Reports/ 2007/Election-2006-Online.aspx, 2007.

[8] Ala-Mutka, K., Malanowski, N., Punie, Y. and Cabrera, M., Active Ageing and the Potential of ICT for Learning. Luxembourg: European Communities, 2008, pg. 19.

[9] Commission for the European Communities, Making a European area of lifelong learning a reality. Brussels: European Commission, 2001, pg. 6.

[10] Commission for the European Communities, i2010 - A European Information Society for Growth and Employment. Brussels: European Commission, 2005.

[11] Commission for the European Communities, Ministerial Declaration on ICT for an Inclusive Society. Accessed 27/6/13 from http://www.ebaltics.com/doc upl/Declaration. pdf?PHPSESSID=718c947c879698696341 $\overline{\mathrm{d}} 5 \mathrm{f} 7 \mathrm{ff1} 154 \mathrm{c} 0 \mathrm{a}$, 2006 .

[12] Commission for the European Communities. Ageing Well in the Information Society. Brussels: European Commission, 2007, pg. 1 .

[13] Selwyn, N., The information aged: A qualitative study of older adults' use of information and communications technology. Journal of Aging Studies, 18(4): 369-384, 2004.
[14] Cameron, D, Marquis, R and Webster, B., Older adults' perceptions, experiences and anxieties with emerging technologies. Australasian Journal on Ageing, 20(3): 50-56, 2001.

[15] Sum, S., Mathews, R. M., Hughes, I., and Campbell, A. Internet use and loneliness older adults. CyberPsychology \& Behavior, 11(2); 208-211, 2008

[16] Adams, N., Stubbs, D., and Woods, V.. Psychological barriers to Internet usage among older adults in the UK. Medical Informatics and the Internet in Medicine, 30 (1); 3-17, 2005

[17] Peacock, S. E., and Kunemund, H., Senior citizens and Internet technology. European Journal of Ageing, 4(4), 191-200, 2007.

[18] Hogeboom, D.L., McDermott, R.J., Perrin, K.M. and Osman, H., Internet use and social networking among middle aged and older adults. Educational Gerontology, 36(2): 93-111, 2009.

[19] Hernández-Encuentra, E., Pousada, M. and Gómez-Zúñiga, B.ICT and older people: Beyond usability. Educational Gerontology, 35(3): 226-245, 2009.

[20] Ng, C., Motivation among older adults in learning computing technologies: A grounded model, Educational Gerontology, 34(1): 1-14, 2008.

[21] Abbey, R. and Hyde, S., No country for older people? Age and the digital divide, Journal of information, Communication and Ethics in Society, 7(4): 225-242.

[22] Zickuhr, K. and Madden, M., Older adults and internet use. Washington, DC: Pew Research Center's Internet \& American Life Project, 2012.

[23] National Statistics Office, Culture participation survey 2011. Malta: National Statistics Office, 2012.

[24] National Statistics Office, ICT usage by enterprises and households 2010. Malta: National Statistics Office, 2011.

[25] Morris, A., E-literacy and the grey digital divide: a review with recommendations. Journal of information literacy, 1(3): 13-28, 2007.

[26] Kiel, J.M., The digital divide: Internet and e-mail use by the elderly. Medical Informatics and the Internet in Medicine, 30(1): 19-23, 2005.

[27] Miles, M.B. and Huberman, A.M., Qualitative data analysis (2nd ed.). Thousand Oakes, CA : Sage, 1994.

[28] Chu, R. J.C.. How family support and Internet self-efficacy influence the effects of e-learning among higher aged adults: Analyses of gender and age differences. Computer \& Education, 55 (1): 255-264, 2010. 